University for Business and Technology in Kosovo

UBT Knowledge Center

Oct 27th, $10: 45$ AM - 12:15 PM

\title{
Statistical control of mutual exchange of details (tenon -mortise ) from beechwood, in some of manufacturing factories of chairs in region of Ferizaj
}

\author{
Blertë Sylejmani \\ University of Applied Sciences, blerta.sylejmanii@outlook.com \\ Rrahim Sejdiu \\ University of Applied Sciences, rrahim.sejdiu@ushaf.net \\ Agron Bajraktari \\ University of Applied Sciences
}

Follow this and additional works at: https://knowledgecenter.ubt-uni.net/conference

Part of the Architecture Commons

\section{Recommended Citation}

Sylejmani, Blertë; Sejdiu, Rrahim; and Bajraktari, Agron, "Statistical control of mutual exchange of details (tenon -mortise ) from beechwood, in some of manufacturing factories of chairs in region of Ferizaj" (2018). UBT International Conference. 20.

https://knowledgecenter.ubt-uni.net/conference/2018/all-events/20

This Event is brought to you for free and open access by the Publication and Journals at UBT Knowledge Center. It has been accepted for inclusion in UBT International Conference by an authorized administrator of UBT Knowledge Center. For more information, please contact knowledge.center@ubt-uni.net. 


\title{
Statistical Control of Mutual Exchange of Details (Tenon- Mortise) From Beech wood, in Some of Manufacturing Factories of Chairs in Region of Ferizaj
}

\author{
Blertë Sylejmani ${ }^{1}$, Rrahim Sejdiu ${ }^{1}$, Agron Bajraktari ${ }^{1}$ \\ ${ }^{1}$ University of Applied Sciences, Adress "Universiteti” - Ferizaj, Kosova
}

\begin{abstract}
Like every manufacturing industry, the wood industry also faces with many challenges. For responding to these challenges, companies need to improve constantly the quality of their products, by using scientific analysis and putting them into use. This study presents statistical process control of the elements of tenon and mortise, based on data analysis, obtained from production. Based on data processing, the conclusions are given by regarding the possibility of cooperation of companies and their mutual exchange. The regular application of control charts, reduces defects and production costs, and keeps open possibilities for collaboration between enterprises, by exchanging certain parts (concrete case "parts of furniture from wood"). The aim of the study, are the possibilities of mutual exchange of parts produced at different factories and the possibility of collecting these elements in a certain place, where could be conducted only the joining process. The subject of the study were three different companies for the production of chairs, in region of Ferizaj, which use the same raw material, but use different types of machinery.
\end{abstract}

Keywords: chair, statistical control, control diagrams, wood.

\section{Introduction}

The reciprocal exchange of details or the interchange is a feature of the elements of the product that each element without any overhaul (without further processing to adapt) can be clamped with other elements of the product, and taking under consideration that the product will be fully completed by certain quality standards while it is being used. (Osmani, 2001).

This feature of the elements is realized with the help of two factors:

The technological factor, where the methods of machining and fastening of the product are defined and,

The exploitation factor, where the appropriate conditions of use of the product should be determined.

In the contemporary conditions of production, where is also used the cooperation and processing of some elements in different factories, interchange is greatly important.

To be realized it is necessary to meet certain conditions, which are:

- The use of verifiable tolerances and placements in practice,

- The appropriate design of the product and marking tolerances in the drawing,

- The possession of machines and equipment where it is possible to produce within the limits of certain tolerances.

- The possession of measuring tools of the required accuracy. 
- The adequate arrangements of control such as wood dryness accuracy, machine working accuracy, tools and molds conditions, climatic conditions in the ward, etc.

The accuracy of detail production is determined by these parameters: (Pandeli Marku, Sotir Dimoshi, 2007/2008):

- The Accuracy of dimensions,

- Corners that form the surfaces and ribs of the detail,

- The accuracy of the geometric shape,

- The accuracy of the mutual position of the surfaces (detailing),

- Surface cleanliness,

- Rough surfaces etc.

The strength of the attachment depends on the type of placement. According to Mr. Ilinskij, for the mortise and tenon, the maximum value is reached with a $+0.3 \mathrm{~mm}$ clamp.

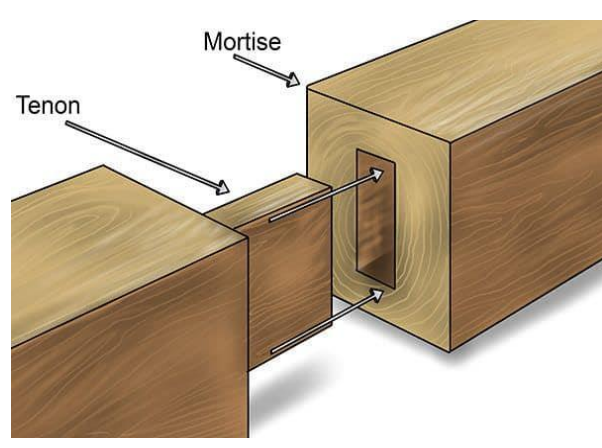

Fig. 1. Mortise and Tenon attachment

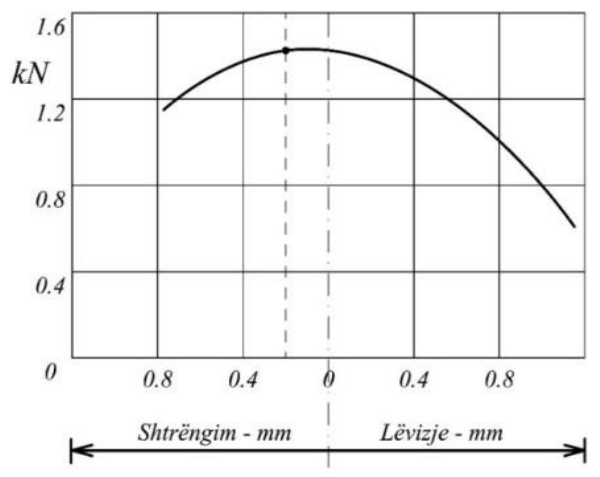

Fig. 2. The strength of attachment

According to Manzhos, the accuracy of processing depends on these factors too:

a) Machines: geometrical accuracy of parts, elastic deformation of parts, thermal deformation, the blunt of blades etc,

b) Tools - geometrical accuracy, elastic thermal deformations, beveling of blades etc,

c) Casting and measuring instrument: the geometric accuracy, the elastic deformations, and tearing.

d) The processor: material properties, which are not of the same size, elastic deformations, internal tensions of the wood, etc.

e) Workshop: the incorrect foundation, the incorrect fixing of the machine, the ineffective mode of operation, the inaccurate measurements etc.

In wood processing, we should always take into account its hygroscopic properties. In this regard, depending on the condition of the surrounding air, the wood receives or releases moisture. Smoke and shrinkage cause the processor or workmanship to change, and, as is known, those dimensional changes are not the same in all directions, so the detail changes shape.

To avoid these consequences the wood will wither to some moisture, depending on the conditions of use. On the one hand, incorrect drying should be calculated and on the other hand, the increase in humidity (lag during enlargement, whitening, and coloring) may occur in the production process. The wood should be dried up to $2 \%$ under the moisture of the exploitation, so if the wood slightly bulges and the bonds will be a little stronger. Much worse is when the opposite happens, because the shrinkage will cause a crack into the wood or to the adjacent line. 
Wood humidity for furniture, depending on the destination and technology, ranges from $6-12 \%$. To keep this moisture unchanged in the course of the production process, it is imperative to condition the air. The limits on permissible relative humidity and air temperature in the technological process are:

$$
\begin{aligned}
& \varphi=35 \div 70 \% \text { (optimal } 55 \%) \text { l.r. ajrit, } \\
& \mathrm{t}=18 \div 25{ }^{\circ} \mathrm{C}\left(\text { optimal } 20{ }^{\circ} \mathrm{C}\right) .
\end{aligned}
$$

To ensure the accuracy of detailing, you should:

a) The wood material should be dried according to the requirements of the technological process. Before processing in machinery, the wood humidity in percentage must not be more than:

- For details of interior doors, wall coating etc. .....12-14\%

- For details of windows, exterior doors etc. ... 15-17\%

- For furniture details........ 10-12\%

- For parquet .........8-10\%

b) In the environment of the production, the temperature should be between $18-25^{\circ} \mathrm{C}$ and relative humidity of the air at $60-65 \%$

- The processing of the details must be carried out on machines with high precision machining.

- The accuracy of the machine registration should be checked systematically.

- Checking the accuracy of the work should be performed with high precision measuring instruments such as calibers.

- The creation of optimum working conditions in terms of cleanliness, lighting, order, etc.

It is difficult to give an analytical link to the impact of each of the factors mentioned above in the accuracy of detailing. However, the most important ones are the three permanent factors: Machine-Detail-Instrument (Pandeli Marku, Sotir Dimoshi, 2007/2008).

\section{The Purposes of the study}

The study aims to:

Establish normal data distribution curves for each enterprise where the samples were taken, Determine the accuracy of the machines for the formation of the mortise and tenon according to the Russian standard GOST,

Build diagrams " $\mathrm{X}$ " and "S" for the measured data,

Set the standard deviation rate for each factory separately,

Analyze the possibilities of cooperation (exchange) of the details between the companies that are under review.

\section{Material and Methods}

\section{Material Used for the Production of Details}

For the production of the details obtained in the study, beech wood (Fagus Sylvatica L) which is grown in the regions: Kamenica, Kaçanik, Jezerc.

\section{Machinery Used for the Production of Details}

To connect the details of the interlocking to a fastening or a product, which is made of wood, it is necessary to form connecting elements, such as mortises and tenons, and so on. Tenons are 
created in the suction machines, which are often called tenoners, while the mortises are created by the means of drilling machines.

\section{Measuring Tools Used to Measure the Details}

The noniuses with $0.01 \mathrm{~mm}$ accuracy are used to measure the mortises and tenons.

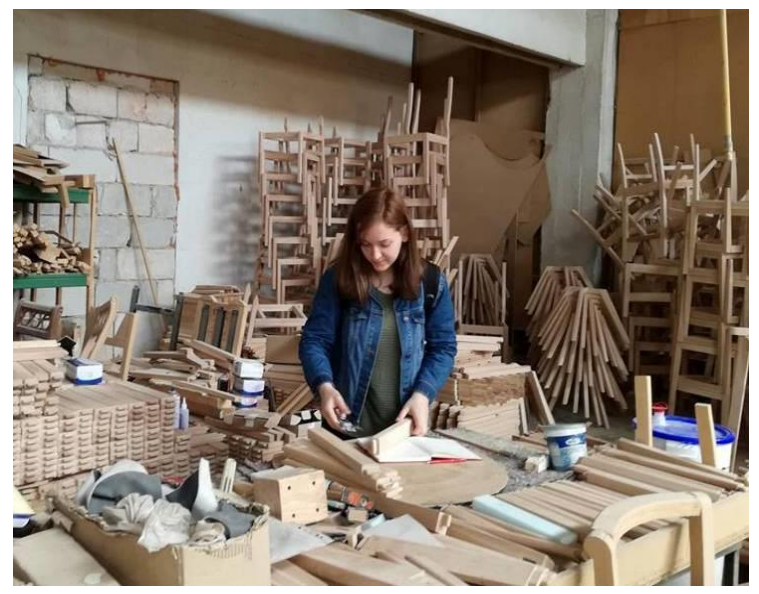

Figure 3. The measuring of details are made with nonius

\section{The Building of Normal and Factual Curve}

After the measuring samples are taken in the terrain for mortises and tenons (60 measurements per each), their processing is done. Using tables and mathematical formulas, we have the results.

Table 1. Recording measurements at certain locations.

\begin{tabular}{|l|l|l|l|l|l|l|}
\hline \multirow{2}{*}{$\begin{array}{l}\text { Number of } \\
\text { details }\end{array}$} & \multicolumn{5}{|c|}{ Recording measurements at certain locations } & \multirow{2}{*}{ Notice } \\
\cline { 2 - 6 } & Dimensions in mm certain places for measurement & \\
\cline { 2 - 6 } & I & II & III & IV & Mesatare & \\
\hline 1 & & & & & & \\
\hline 2 & & & & & & \\
\hline$\sum=\mathrm{N}$ & & & & & & \\
\hline
\end{tabular}

The number of groups is set according to the formula:

$$
I=2 \sqrt[3]{N}=2 \sqrt[3]{60}=8
$$

$\mathrm{N}$ - The number of total controlled details (concrete case 60).

The limits between groups is calculated by using the formula: 


$$
R_{i}=\frac{d_{\max }-d_{\min }}{I}
$$

$d_{\max }$ - The maximum value of the average of the groups.

$d_{\min }$ - The minimum value of the average of the groups.

Table 2. The table for construction of factual curve.

\begin{tabular}{|c|c|l|l|l|l|l|l|}
\hline $\begin{array}{c}\text { Number } \\
\text { of } \\
\text { groups }\end{array}$ & $\begin{array}{c}\text { Limits } \\
\text { of } \\
\text { groups }\end{array}$ & $\begin{array}{c}\text { Average } \\
\text { of } \\
\text { groups }\end{array}$ & $\begin{array}{c}\text { Frequency } \\
\text { (f) }\end{array}$ & $\mathbf{X} * \mathbf{F}$ & $\begin{array}{l}(\mathrm{X}- \\
\mathbf{M})\end{array}$ & $\begin{array}{l}(\mathbf{X}- \\
\mathbf{M}) 2\end{array}$ & $\begin{array}{l}(\mathbf{X}- \\
\mathbf{M}) 2 * \mathbf{F}\end{array}$ \\
\hline 1 & & & & & & & \\
\hline 2 & & & & & & & \\
\hline$\Sigma$ & & $\mathrm{N}=60$ & & & & \\
\hline
\end{tabular}

The arithmetic average is determined by the formula:

$$
M=\frac{\sum X F}{N}
$$

While the standard deviation is determined according to the formula:

$$
\delta=\sqrt{\frac{\sum(X-M)^{2} F}{N-1}(4)}
$$

\begin{tabular}{|c|c|c|c|c|c|}
\hline \multicolumn{6}{|c|}{$Y_{m}=\frac{0,4 R_{i} N}{\delta}$} \\
\hline \multicolumn{2}{|c|}{ Deviation \pm from $M$} & \multicolumn{2}{|c|}{ Abscissa in $\mathrm{mm}$} & \multirow{2}{*}{ Coefficient $h$} & \multirow{2}{*}{$\begin{array}{l}\text { The high } \\
\text { of the } \\
\text { ordinate }\end{array}$} \\
\hline Në pjesë & Në mm & Majtas (-) & Djathtas $(+)$ & & \\
\hline 0 & & & & 1.00 & \\
\hline 0.5 & & & & 0.883 & \\
\hline 1 & & & & 0.607 & \\
\hline 1.5 & & & & 0.385 & \\
\hline 2 & & & & 0.135 & \\
\hline 2.5 & & & & 0.044 & \\
\hline 3 & & & & 0.11 & \\
\hline
\end{tabular}

To construct the normal curve, it is used the table:

Table 3. The table for normal curve construction.

When it is known the value of standard deviation, then according to Russian standard GOST, it is easy to find the accuracy of the machine's work, which is as follows:

$$
c=\frac{133 \cdot \sigma}{\sqrt[3]{d+20}}
$$


Table 4. The assignment of machine accuracy:

\begin{tabular}{|c|c|c|c|c|c|c|c|c|}
\hline The degree of accuracy & 1 & 2 & $2-\mathrm{a}$ & 3 & $3-\mathrm{a}$ & 4 & $4-\mathrm{a}$ & 5 \\
\hline Cecoeficient & 1 & 2 & 3 & 4 & 6 & 10 & 12 & 16 \\
\hline \multirow{3}{*}{ Nominal size in mm } & \multicolumn{7}{|c|}{ The degree of accuracy } \\
\cline { 2 - 10 } & 1 & 2 & $2-\mathrm{a}$ & 3 & $3-\mathrm{a}$ & 4 & $4-\mathrm{a}$ & 5 \\
\hline & 0.13 & 0.25 & 0.37 & 0.50 & 0.75 & 1.00 & 1.50 & 2.00 \\
\hline $1-10$ & 0.15 & 0.30 & 0.45 & 0.60 & 0.90 & 1.20 & 1.80 & 2.40 \\
\hline $10-18$ & 0.18 & 0.35 & 0.52 & 0.70 & 1.05 & 1.40 & 2.10 & 3.00 \\
\hline $18-30$ & 0.20 & 0.40 & 0.60 & 0.80 & 1.20 & 1.60 & 2.40 & 3.00 \\
\hline $30-50$ & 0.23 & 0.45 & 0.67 & 0.90 & 1.35 & 1.80 & 2.70 & 4.00 \\
\hline $50-80$ & 0.25 & 0.50 & 0.75 & 1.00 & 1.50 & 2.00 & 3.00 & 4.00 \\
\hline $50-120$ & 0.30 & 0.60 & 0.90 & 1.20 & 1.80 & 2.40 & 3.60 & 5.00 \\
\hline $120-260$ & 0.35 & 0.70 & 1.05 & 1.40 & 2.10 & 2.80 & 4.20 & 6.00 \\
\hline $260-500$ & 0.40 & 0.85 & 1.30 & 1.70 & 2.50 & 3.40 & 5.10 & 7.00 \\
\hline $500-800$ & 0.50 & 1.00 & 1.50 & 2.00 & 3.00 & 4.00 & 6.00 & 8.00 \\
\hline $800-1250$ & & & & & & & & \\
\hline
\end{tabular}

Russian standard GOST 644953 calculates the machine's accuracy depending on the size of the processor using the formula $\Delta=6 \sigma$. Based on this and knowing the nominal size of the processor is found the accuracy of the machine.

The choice of the diagram was made according to the figure (Vincent K. Omachonu, Joel E. Ross, 2004):

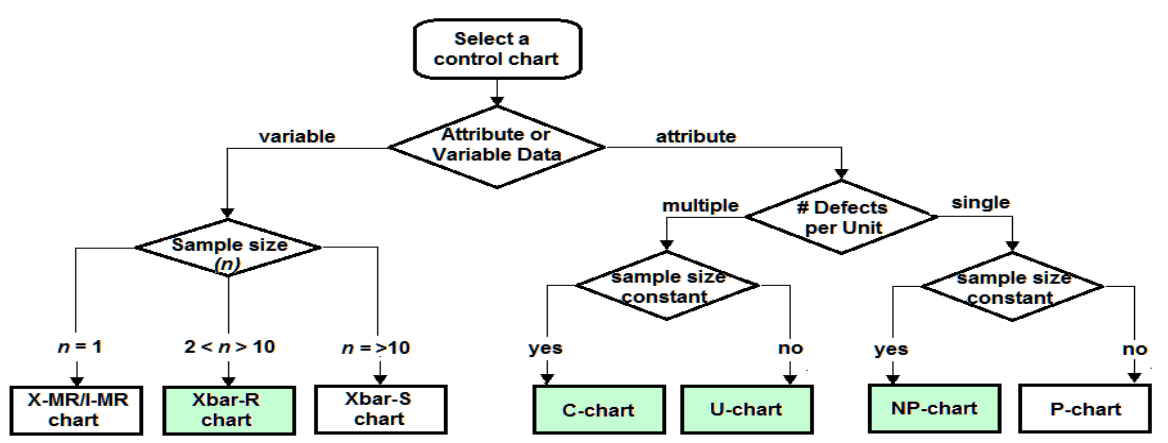

Figure 4. The choice of control cards

As it is seen from the figure and taking into account the number of measured samples (60) it turns out that for the review we will get the diagram $\overline{\mathrm{X}}$ and $\mathrm{S}$.

In the following table are given formulas for calculations of the above diagrams. 


\begin{tabular}{|c|c|c|}
\hline Diagram & Control limits of $3 \sigma$ & Central line \\
\hline$X$ & $\bar{X} \pm \frac{3 \overline{M R}}{d_{2}}$ & $\overline{\boldsymbol{X}}$ \\
\hline$\overline{\boldsymbol{X}}$ (using R diagram) & $\overline{\bar{X}} \pm A_{2} \bar{R}$ & $\overline{\bar{X}}$ \\
\hline$\overline{\boldsymbol{X}}$ (using S diagram) & $\overline{\bar{X}} \pm A_{3} \bar{S}$ & $\overline{\bar{X}}$ \\
\hline 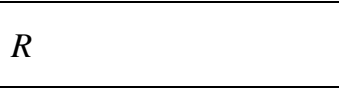 & $\begin{aligned} U C L & =D_{4} \bar{R} \\
L C L & =D_{3} \bar{R}\end{aligned}$ & $\overline{\boldsymbol{R}}$ \\
\hline$M R$ & $\begin{array}{l}U C L=D_{4} \overline{M R} \\
L C L=D_{3} \overline{M R}\end{array}$ & $\overline{M R}$ \\
\hline$S$ & $\begin{aligned} U C L & =B_{4} \bar{S} \\
L C L & =B_{3} \bar{S}\end{aligned}$ & $\overline{\boldsymbol{S}}$ \\
\hline
\end{tabular}

The required coefficients for the calculation of the data are presented in the following table:

Table 5. Factors of control diagrams.

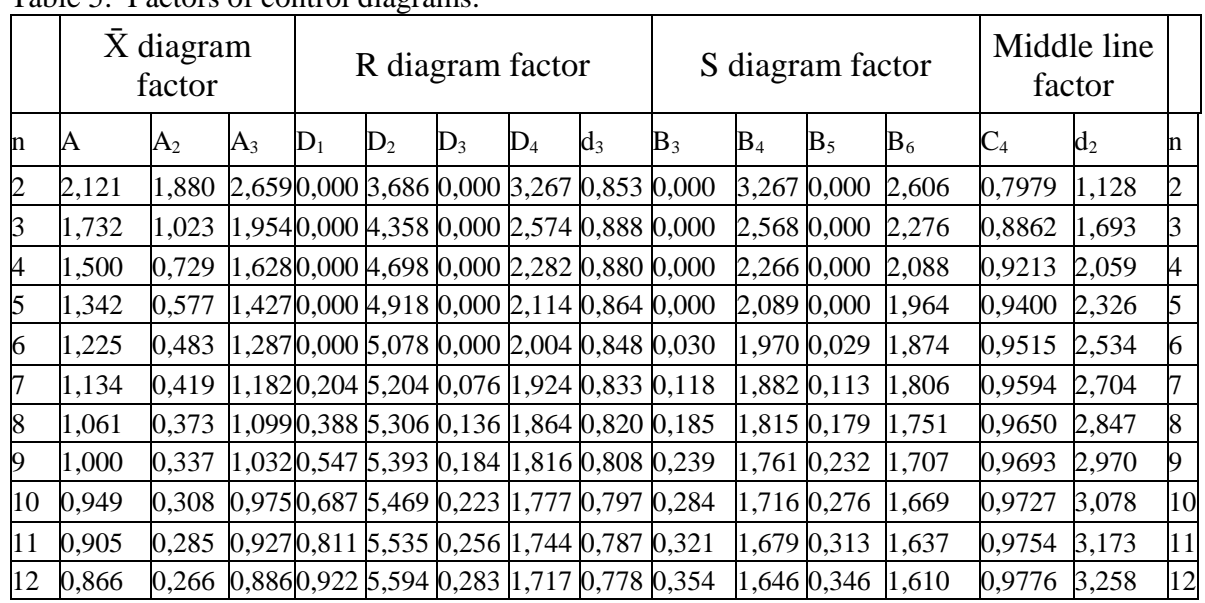

The general terminology used in the control charts is as follows:

$m=$ number of samples or subgroups,

$n=$ number of observations for each sample,

$x_{i}=$ the value (measurement) of an individual item

$\bar{x}=$ sample average $=\frac{x_{1}+x_{2}+x_{3}+\cdots+x_{n}}{n}$ (6)

$\overline{\bar{X}}=$ average of the sample average $=\frac{\sum_{i=1}^{m} \bar{x}_{i}}{m}$

$R=$ sample rank $=x_{\text {max }}-x_{\text {min }}$

$\bar{R}=$ average rank $=\frac{R_{1}+R_{2}+R_{3}+\cdots+R_{m}}{m}=\frac{\sum_{i=1}^{m} R_{i}}{m}$

$=$ sample standard deviation $=\sqrt{\frac{\sum_{i=1}^{n}\left(x_{i}-\bar{x}\right)^{2}}{(n-1)}}$ 
$\bar{S}=$ average of standard deviation of sample $=\frac{S}{m}(10)$

$U C L$ - upper limit of control,

$L C L$ - lower limit of control..

\section{Results}

After collecting the sample data, it is necessary to analyze the results:

- To determine the standard deviation limits, by measuring the variability of the data and finding the arithmetic average of the variation. The smaller the standard deviation is the individual values of the variables are concentrated closer to the arithmetic average. The greater the standard deviation is the individual values of the variables are scattered beyond the arithmetic average.

- To determine if the process is statistically controlled and if the data is damaged. In the analysis of the control table $\mathrm{X}$ bar and $\mathrm{S}$ bar it is necessary to analyze the components $\mathrm{X}$ and $\mathrm{S}$, and determine whether the measurements are out of control, and

- To determine the nature of the data distribution that are studied and how many times the values are repeated within the groups. In the analysis of the distribution of data, it is necessary to construct the normal theoretical curve and the actual distribution range of the detail groups (Gaussian curvature).

\section{Diagram X and S for "A" Factory.}

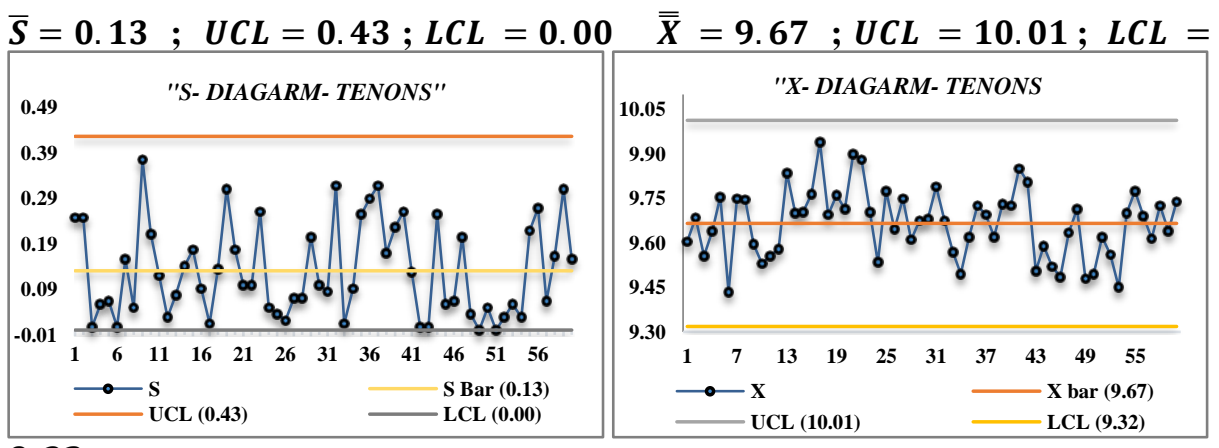

9.32 ;

Figure 5. "X \& S" chart - tenons of "A" factory. 


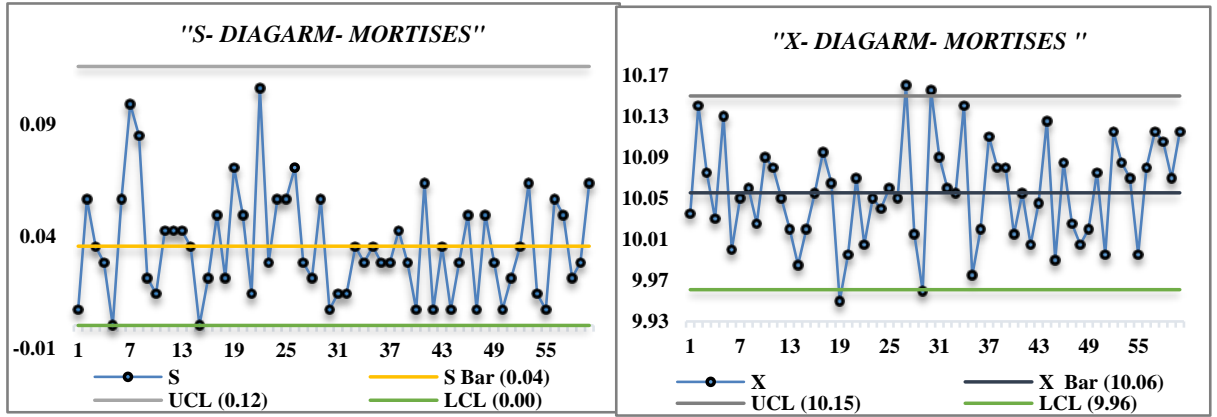

Figure 6. "X \& S" chart - mortises of "A" factory.

The results obtained from the $\mathrm{X}, \mathrm{S}$ diagrams from the tenon samples in factory "A" show that the process of tenon production is operating under control, and there has been no defect during the tenon process. While the results obtained from the diagram $\mathrm{S}$ for samples of mortises show that the process is within the control limits but there are indications that some of the points may fall below the limits. After the X-diagram formortises, we notice that three points are out of control, which means that the process in this case is not operating in control and has caused errors during the mortise formation.

Mortise St.dev $=0.05 \mathrm{~mm} ;$ Tenon St.dev $=0.11 \mathrm{~mm}$;

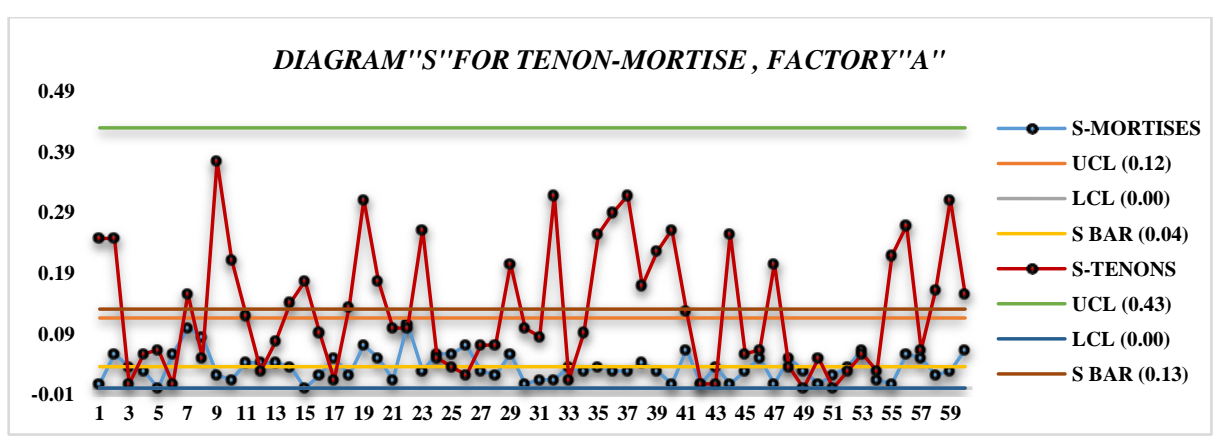

Figure 7. "S" chart - the comparison between tenons \& mortises of "A" factory.

In the case of the structure of the "S" diagram for the comparison of samples tenon-mortise, the graph clearly shows that the larger standard deviation has dips for the formation of the tenons (st.dev .: 0.11), while the diagram for the forming of the mortises seems to be closer to the arithmetic average and have a lower standard deviation (st.dev.:0.05), which means that the mortise-forming machine is more accurate than the tenon forming (within the factory). 
$\overline{\bar{X}}-$ Mortise $=10.06 ; \quad \overline{\bar{X}}-$ Tenon $=9.97 \mathrm{~mm} ;$

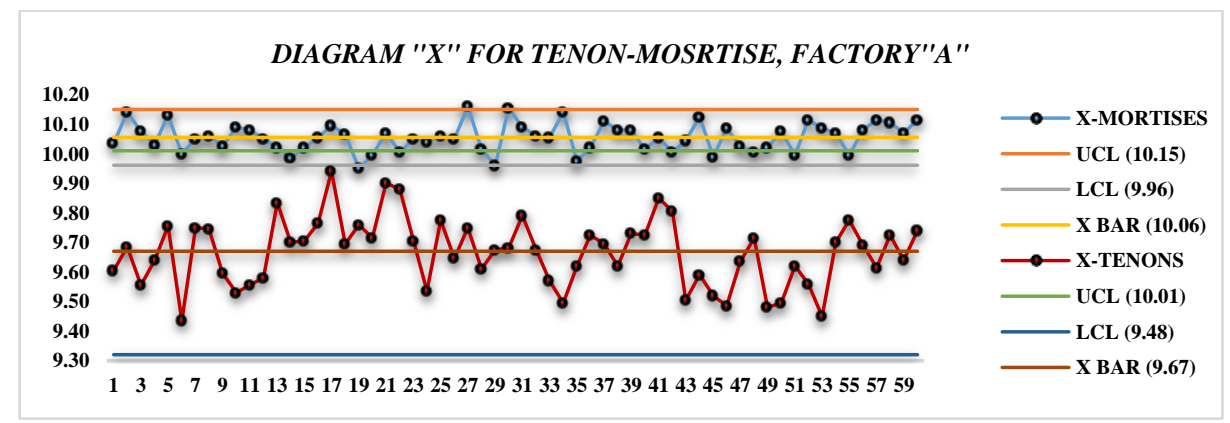

Figure 8. " $\mathrm{X}$ " chart - the comparison between tenons \& mortises of " $\mathrm{A}$ " factory.

The mortise-shaped " $\mathrm{X}$ " structure diagram shows that the connections between the tenons and the mortises are loose, without tightening of the details and the tolerance between the tenons and mortises for the factory "A" is $(10.06-9.97)=0.39 \mathrm{~mm}$.

The Normal Gaussian Curve, and Factual Polygon of the Dimensions Distribution for "A" Factory.

Tenons (St.dev. $=0.11 ; I=9 ; M=9.67 ; c=4.88 ; \Delta=0.68 ;$ )

Mortises (St.dev. $=0.05 ; \quad I=9 ; \quad M=10.06 ; c=2.09 ; \Delta=0.29 ;$ )
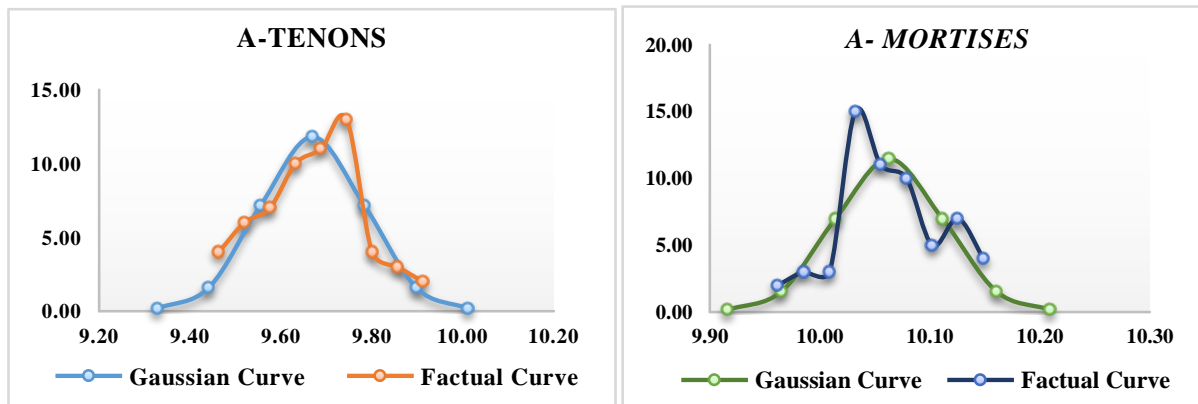

Figure 9. Construction of Gaussian curve and factical curve for tenons and mortises.

According to the curves obtained from the tenon-mortise samples, in first case for tenon samples, most of the points have fallen between 0 and $\sigma$, and there is no point out of the control limits. In second case for mostrise details, most of the points have fallen between 0 and $-\sigma$, and there is no point out of the control limits, but even though the subgroup statistics are within the control limits, the process has shown a absence of statistical control. There are other factors that indicate dhe absence of control that should be studied. 
Determination of the Scale Machine Accuracy for Tenons and Mortises According to the Russian Standard Gost, for "A" Factory.

Table 6. Determination of the scale machine accuracy.

\begin{tabular}{|c|c|c|c|c|c|c|c|c|}
\hline The degree of accuracy & 1 & 2 & $2-\mathrm{a}$ & 3 & $3-\mathrm{a}$ & 4 & $4-\mathrm{a}$ & 5 \\
\hline C coefficient & 1 & 2 & 3 & 4 & 6 & 10 & 12 & 16 \\
\hline \multirow{3}{*}{ Nominal size in mm } & \multicolumn{9}{|c|}{0 (GOST } \\
\cline { 2 - 10 } & \multicolumn{2}{|l|}{ The degree of accuracy } \\
\cline { 2 - 10 } & 1 & 2 & $2-\mathrm{a}$ & 3 & $3-\mathrm{a}$ & 4 & $4-\mathrm{a}$ & 5 \\
\hline $1-10$ & 0.13 & 0.25 & 0.37 & 0.50 & 0.75 & 1.00 & 1.50 & 2.00 \\
\hline $10-18$ & 0.15 & 0.30 & 0.45 & 0.60 & 0.90 & 1.20 & 1.80 & 2.40 \\
\hline $18-30$ & 0.18 & 0.35 & 0.52 & 0.70 & 1.05 & 1.40 & 2.10 & 3.00 \\
\hline
\end{tabular}

The accuracy of the machine is shown in the table 6., according to the Russian standard GOST. From the measured samples, we get the coefficient $C$ and through it, we determine the accuracy of the machine through standard deviation. In this case, the nominal size of tenons and mortises is $10 \mathrm{~mm}$. We find that for tenons of $10 \mathrm{~mm}$ dimension, and the coefficient 4.88 (the nearest coefficient is 4), the degree of accuracy is 0.60 . While for mortises with $10 \mathrm{~mm}$ dimensions and a coefficient of 2.09 (the nearest coefficient is 2), the accuracy of the machine is 0.30 .

\section{Diagram X and S for "B" Factory.}

$\bar{S}=0.15 ; U C L=0.47 ; L C L=0.00 \quad \overline{\bar{X}}=10.21 ; U C L=10.51 ; L C L=9.73$;

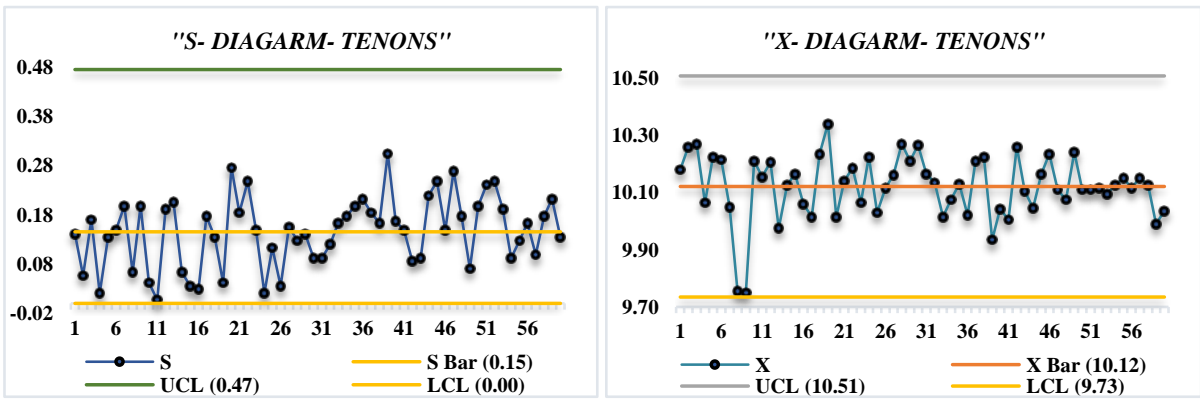

Figure 10. "X \& S" chart - tenons of "B" factory. 


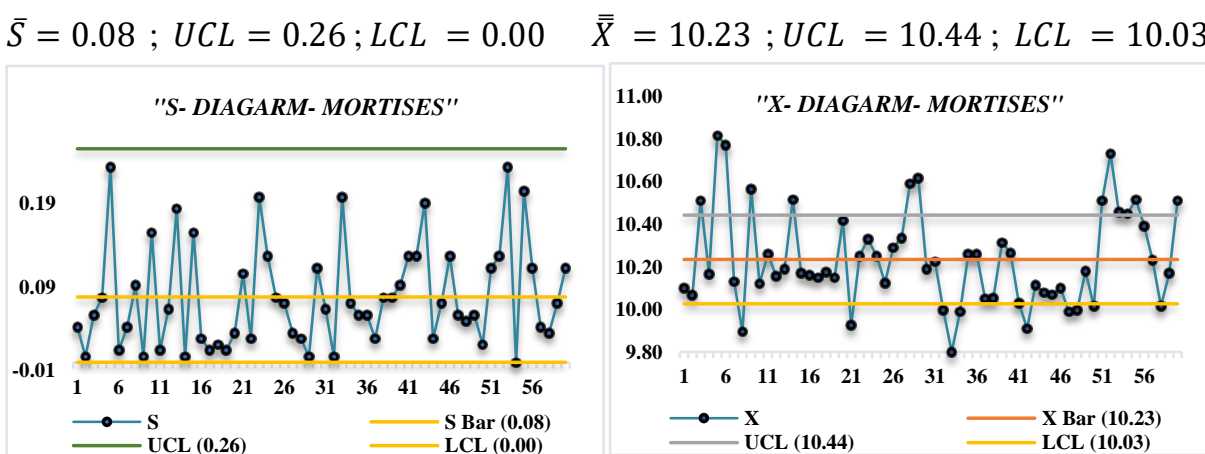

Figure 11. "X \& S" chart - mortises of "B" factory.

The results obtained from the $\mathrm{X}, \mathrm{S}$ diagrams from the tenon samples at factory "B" show that the tenon production process is operating under control, and there has been no defect during the process. While the results obtained from the $\mathrm{S}$ diagram for the mortise samples indicate that the process is within the control limits, but the sample distribution lies further away from the central line, and the risk of falling out of points is greater. Because of the structure of the $\mathrm{X}$ diagram for mortises, we notice that 22 points are out of control, which means that the process in this case is not operating under control and has caused errors during the formation of the mortises.

Mortise St.dev $=0.11 \mathrm{~mm} ; \quad$ Tenon St.dev $=0.22 \mathrm{~mm}$;

DIAGRAM "S" FOR TENON MORTISE, FACTORY "B"
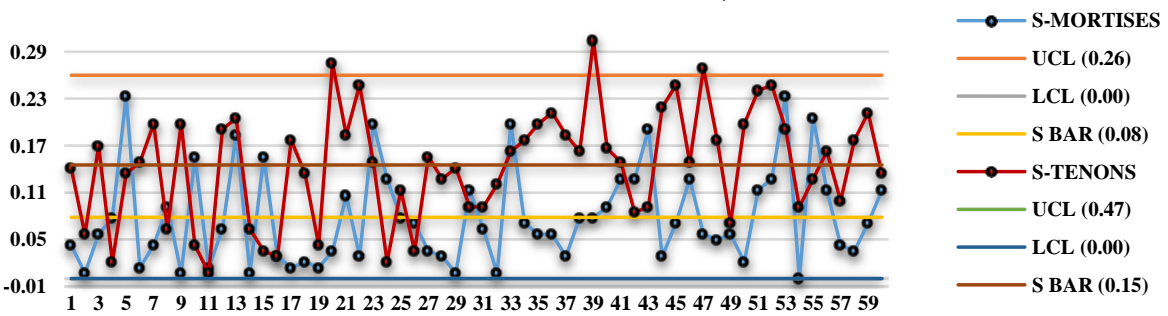

Figure 12. "S" chart - the comparison between tenons \& mortises of "B" factory.

In the case of the structure of " $\mathrm{S}$ " diagram for the comparison of samples tenon-mortise, the graph clearly shows that the larger standard deviation has dips for the formation of the tenons (st.dev . : 0.22). While the diagram for the forming of the mortises seems to be closer to the arithmetic average and have a lower standard deviation, (st.dev. :0.11), which means that the mortise-forming machine is more accurate than the tenon forming (within the factory). 
$\overline{\bar{X}}-$ Mortise $=10.23 ; \quad \overline{\bar{X}}-$ Tenon $=10.12 \mathrm{~mm} ;$

Figure 13. "X" chart - the comparison between tenons \& mortises of " $\mathrm{B}$ " factory.

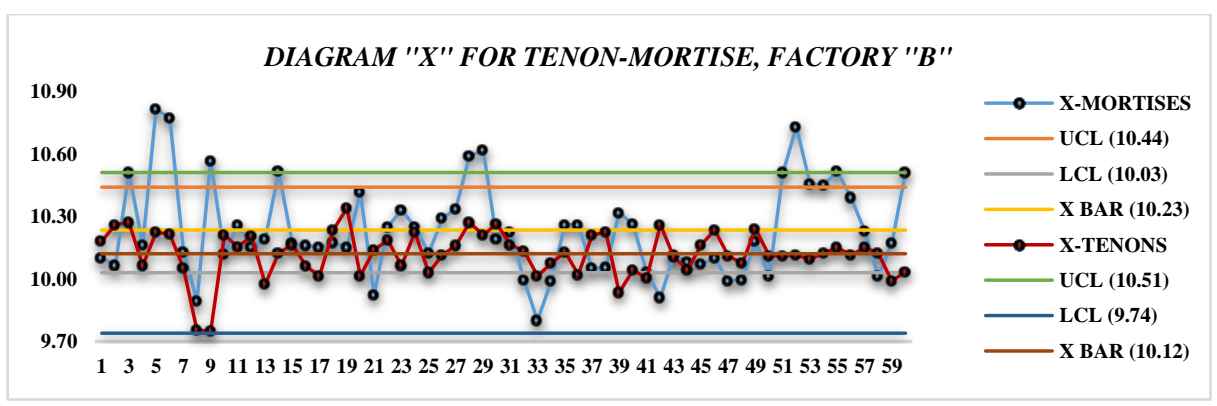

The mortise-shaped " $\mathrm{X}$ " structure diagram shows that the connections between the tenons and the mortises are loose, without tightening of the details and the tolerance between the tenons and mortises for the factory "B" is $(10.23-10.12)=0.11 \mathrm{~mm}$.

\section{The Normal Gaussian Curve, and Factual Polygon of the Dimension Distribution for "B" Factory.}

Tenons (St.dev. $=0.11 ; \quad I=9 ; \quad M=10.12 ; c=4.80 ; \Delta=0.66 ;$ )

Mortises (St.dev. $=0.22 ; \quad I=9 ; M=10.23 ; c=9.61 ; \Delta=1.35$;)

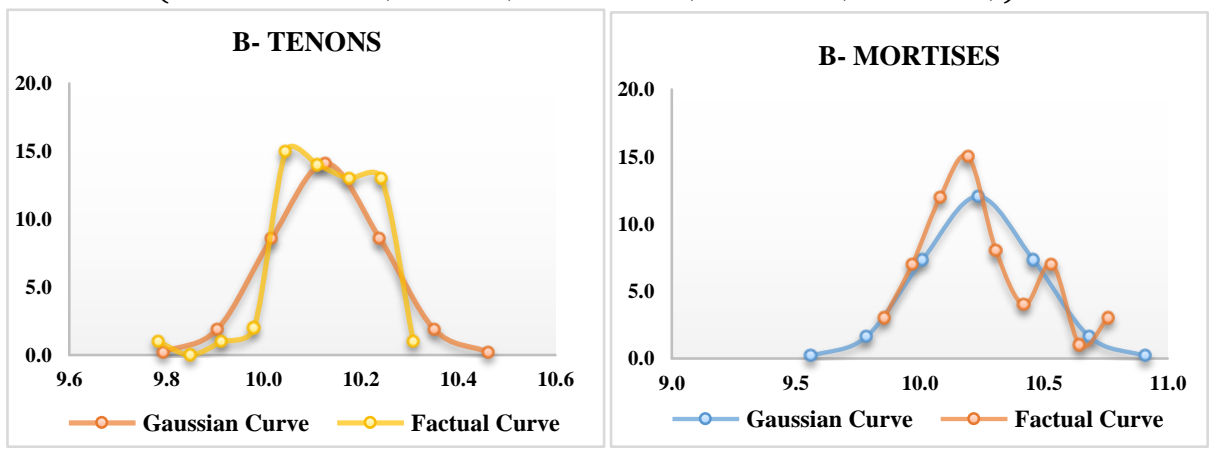

Figure 14. Construction of Gaussian curve and factical curve for tenons and mortises.

According to the curves obtained from the tenon-mortise samples, in first case of tenon samples, most of the points have fallen between 0 and $-\sigma$, and there are points out of the control limits. So in this chart the process of tennon forming, shows abscence of statistical control. And there sems to be damages in products after production. In second case of mostrise details, most of the points have fallen between 0 and $-\sigma$, and there is no point out of the control limits, but even though the subgroup statistics are within the control limits, the process has shown a absence of statistical control. 
Determination of The Scale Machine Accuracy for Tenons and Mortises According to the Russian Standard Gost, for "B" Factory.

Table 7. Determination of the scale machine accuracy.

\begin{tabular}{|c|c|c|c|c|c|c|c|c|}
\hline The degreee of accuracy & 1 & 2 & $2-a$ & 3 & $3-a$ & 4 & $4-a$ & 5 \\
\hline C coefficient & 1 & 2 & 3 & 4 & 6 & 10 & 12 & 16 \\
\hline \multirow{2}{*}{ Nominal size in $\mathrm{mm}$} & \multicolumn{5}{|c|}{ The degreee of accuracy } & \multicolumn{2}{|c|}{ (GOST } & 6449-53) \\
\hline & 1 & 2 & $2-a$ & 3 & $3-a$ & 4 & 4-a & 5 \\
\hline $1-10$ & 0.13 & 0.25 & 0.37 & 0.50 & 0.75 & 1.00 & 1.50 & 2.00 \\
\hline $10-18$ & 0.15 & 0.30 & 0.45 & 0.60 & 0.90 & 1.20 & 1.80 & 2.40 \\
\hline $18-30$ & 0.18 & 0.35 & 0.52 & 0.70 & 1.05 & 1.40 & 2.10 & 3.00 \\
\hline
\end{tabular}

The accuracy of the machine scale is found in the table 7., according to the Russian standard GOST. From the measured samples, we get the coefficient $\mathrm{C}$ and we determine the scale of accuracy through it. In this case, the nominal size of tenons and mortises is $10 \mathrm{~mm}$ and the coefficient is 4.80 (the nearest coefficient is 4) that the scale of accuracy is 0.60 . While for mortises with $10 \mathrm{~mm}$ and the dimension of the coefficient and 9.61 (the nearest coefficient is 4) the accuracy scale of the machine is 1.20 .

\section{Diagram X and S for "C" Factory}

$\bar{S}=0.25 ; U C L=0.83 ; L C L=0.00 \quad \overline{\bar{X}}=10.25 ; U C L=10.93 ; L C L=9.57$;

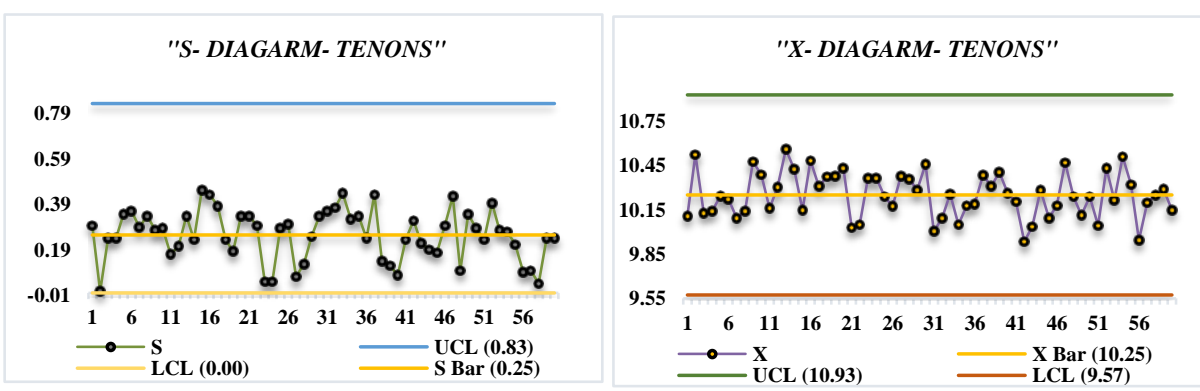

Figure 15. "X \& S" chart - tenons of "C" factory. 
$\bar{S}=0.07 ; U C L=0.21 ; L C L=0.00 \quad \overline{\bar{X}}=10.44 ; U C L=10.61 ; L C L=10.26$;

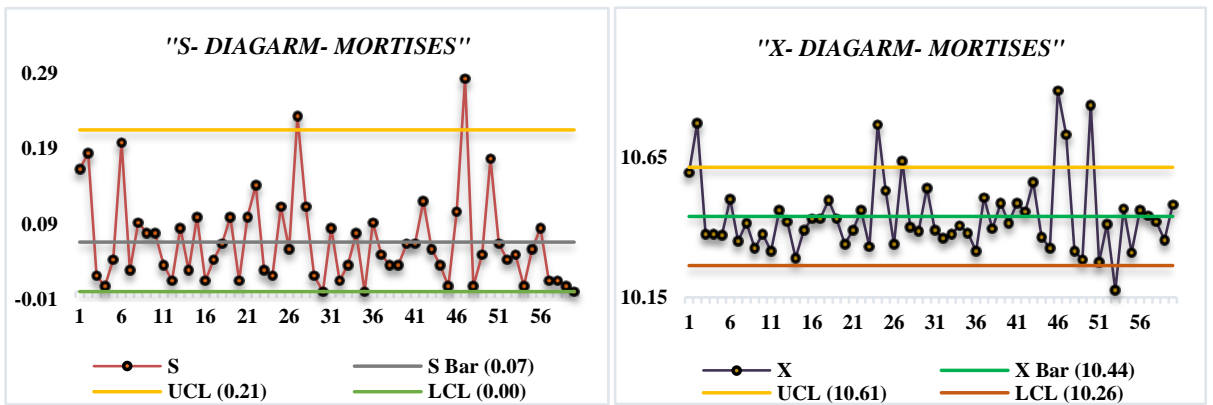

Figure 16. "X \& S" chart - mortises of "C" factory.

The results obtained from the $\mathrm{X}, \mathrm{S}$ diagrams from the tenon samples at factory " $\mathrm{C}$ " show that the tenon production process is operating under control, and there has been no defect during the process. While the results obtained from the $\mathrm{S}$ diagram for the mortise samples indicate that, the process is within the control limits. However, the sample distribution lies further away from the central line and in the case of the structure of the S diagram as well as for X, we notice that 2 points are out of control in diagram $\mathrm{S}$, while in diagram $\mathrm{X}$ are 7 points out of control limits.

Mortise St.dev $=0.14 \mathrm{~mm} ;$ Tenon St.dev $=0.15 \mathrm{~mm}$;

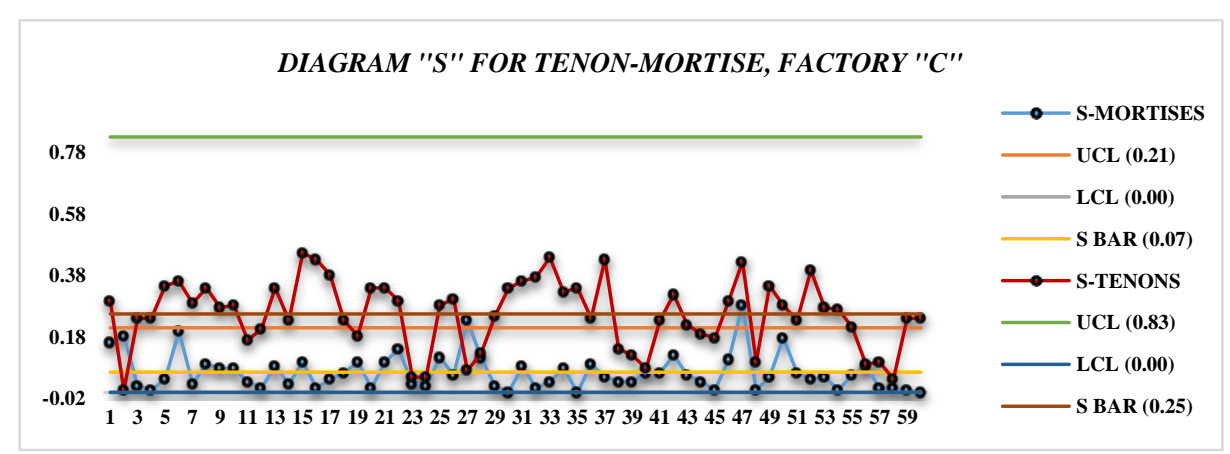

Figure 17. "S" chart - the comparison between tenons \& mortises of " $\mathrm{C}$ " factory.

In the case of the structure of the "S" diagram for the comparison of samples tenon-mortise, the graph clearly shows that the larger standard deviation has dips for the formation of the tenons (st.dev .: 0.15), while the diagram for the forming of the mortises seems to be closer to the arithmetic average and have a lower standard deviation (st.dev.:0.14), which means that the mortise-forming diagram is more accurate because it does not have any points out of control. 
$\overline{\bar{X}}-$ Mortise $=10.44 ; \quad \overline{\bar{X}}-$ Tenon $=10.25 \mathrm{~mm} ;$

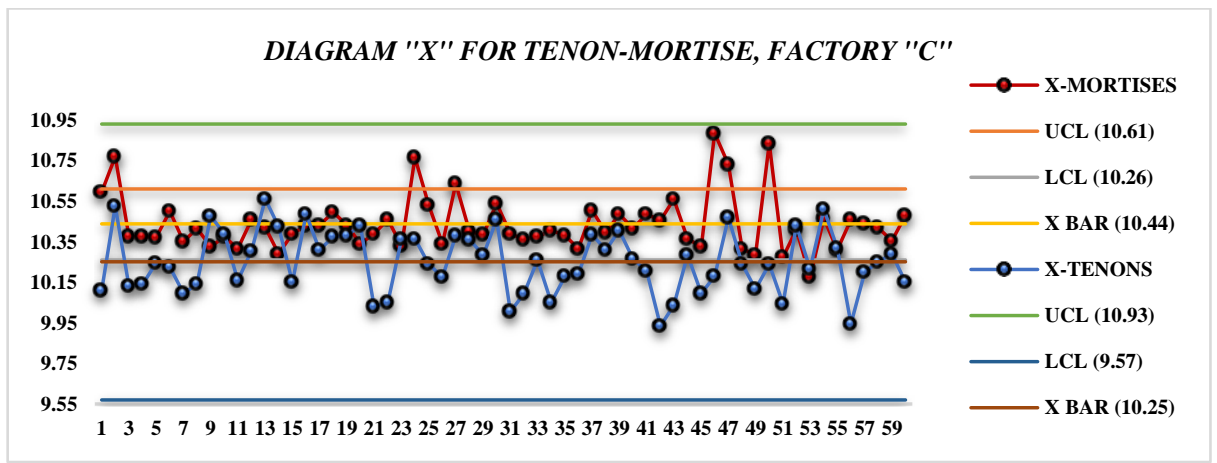

Figure 18. "X" chart - the comparison between tenons \& mortises of " $C$ " factory.

The mortise-shaped "X" structure diagram shows that the connections between the tenons and the mortises are loose, without tightening of the details and the tolerance between the tenons and mortises for the factory "C" is $(10.44-10.25)=0.19 \mathrm{~mm}$.

The Normal Gaussian Curve, and Factual Polygon of the Dimensions Distribution for "C" Factory.

Tenons (St.dev. $=0.15 ; \quad I=9 ; \quad M=10.25 ; c=6.53 ; \Delta=0.92 ;$ )

Mortises (St.dev. $=0.14 ; \quad I=9 ; M=10.44 ; c=5.85 ; \Delta=0.82 ;$ )
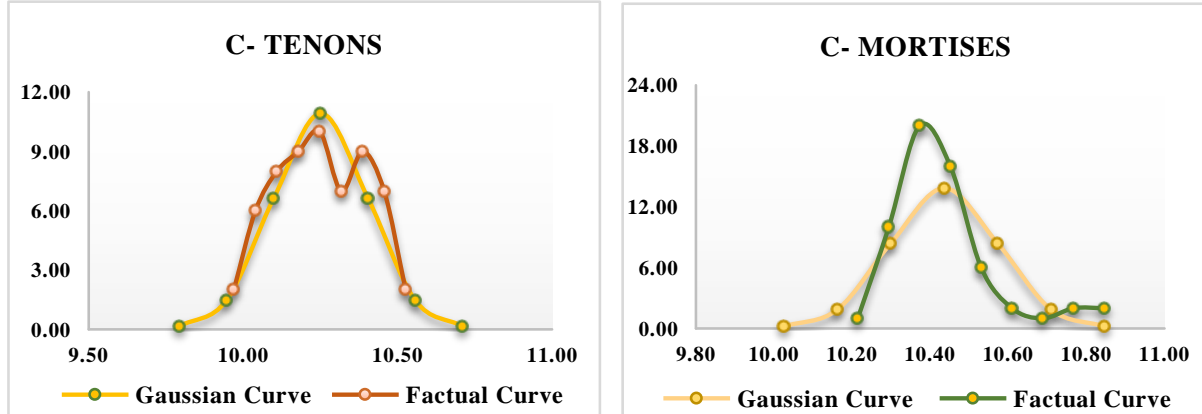

Figure 19. Construction of Gaussian curve and factical curve for tenons and mortises.

According to the curves obtained from the tenon-mortise samples, in first case of tenon samples, most of the points have fallen in the middle of normal curve (point 0 ) and there is no point out of the control limits, but even though the subgroup statistics are within the control limits, the process has shown a absence of statistical control. In second case of mostrise details, most of the points have fallen between 0 and $-\sigma$, and there is no point out of the control limits. 
Determination of the Scale Machine Accuracy for Tenons and Mortises According to the Russian Standard Gost, for "B" Factory.

Table 8. Determination of the scale machine accuracy.

\begin{tabular}{|c|c|c|c|c|c|c|c|c|}
\hline The degree of accuracy & 1 & 2 & $2-\mathrm{a}$ & 3 & $3-\mathrm{a}$ & 4 & $4-\mathrm{a}$ & 5 \\
\hline C coefficient & 1 & 2 & 3 & 4 & 6 & 10 & 12 & 16 \\
\hline \multirow{3}{*}{ Nominal size in mm } & \multicolumn{7}{|c|}{ The degreee of accuracy } \\
\cline { 2 - 10 } & 1 & 2 & $2-\mathrm{a}$ & 3 & $3-\mathrm{a}$ & 4 & $4-\mathrm{a}$ & 5 \\
\hline $1-10$ & 0.13 & 0.25 & 0.37 & 0.50 & 0.75 & 1.00 & 1.50 & 2.00 \\
\hline $10-18$ & 0.15 & 0.30 & 0.45 & 0.60 & 0.90 & 1.20 & 1.80 & 2.40 \\
\hline $18-30$ & 0.18 & 0.35 & 0.52 & 0.70 & 1.05 & 1.40 & 2.10 & 3.00 \\
\hline
\end{tabular}

According to the curves obtained from tenon-mortise samples, both process have been defective and there are points that have been spread out of the Gauss curve. The standard deviation in this case is for the tenon samples is 0.15 , whereas for the mortise samples is 0.14 . The accuracy of the machine scale is found in the table 8., according to the Russian standard GOST.

From the measured samples, we get the coefficient $C$ and determine the scale of accuracy of the machine through it. In this case, the nominal size of tenon and mortise is $10 \mathrm{~mm}$ and the coefficient 6.53 (the nearest coefficient is 6 ) that the accuracy of the machine is 0.90 . For mortise with a $10 \mathrm{~mm}$ dimension and a coefficient of 5.85 (the approximate coefficient is 6), the accuracy of the machine is 0.90 .

\section{The Comparison of Diagrams from Factories "A, B \& C" for Tenon and} Mortise Samples

St. dev. "A" Tenons $=0.11$;

St. dev. "B" Tenons $=0.11$;

St. dev. "C" Tenons $=0.15$;

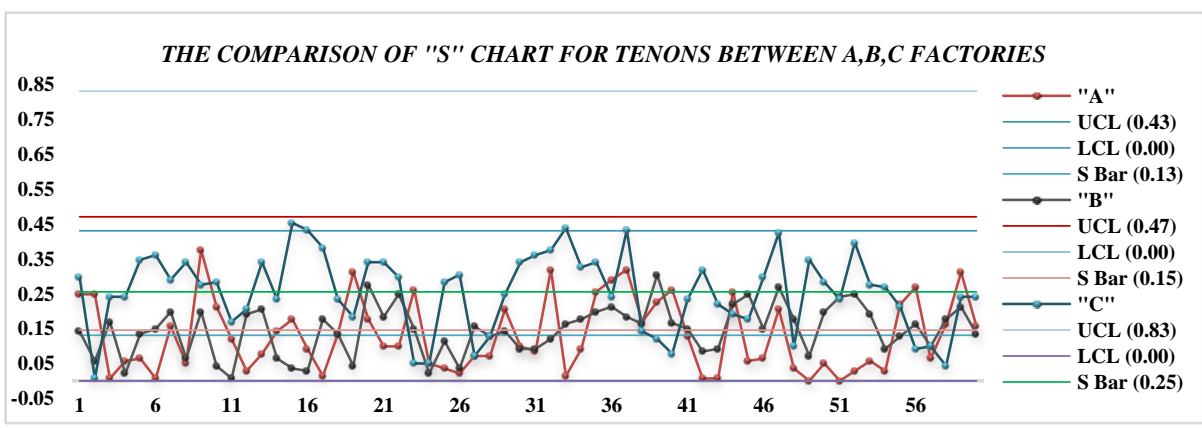

Figure 20. The comparison of standard deviation of tenons, between "A,B,C" factories. 
$\overline{\bar{X}} " \mathrm{~A} "$ Tenons $=0.9 .67 ; \quad \overline{\bar{X}}$ "B" Tenons $=10.12 ; \quad \overline{\bar{X}}$ "C" Tenons $=10.25 ;$

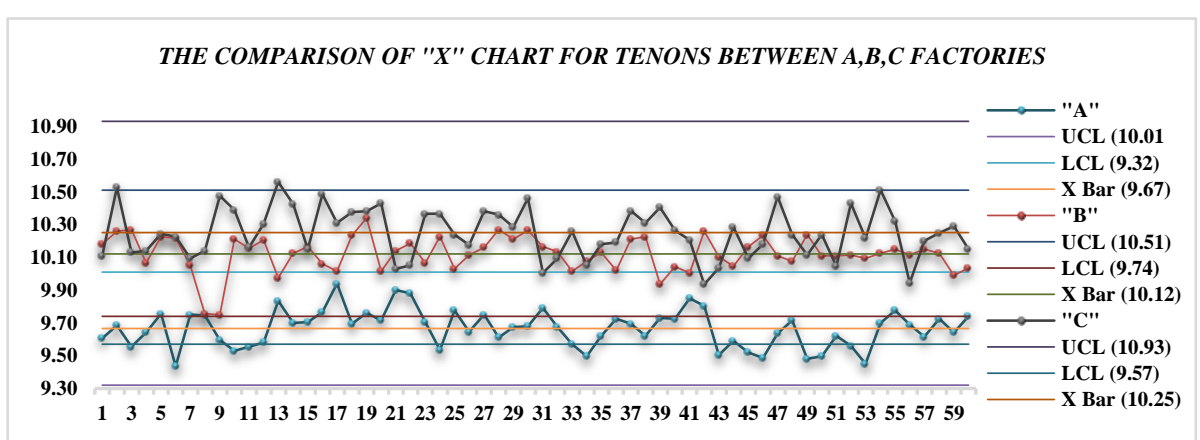

Figure 21. The comparison of arithmetic average of tenons, between "A,B,C" factories.

According to the diagram "S" with the tenons data for factories "A, B, C", we find that based on the standard deviation obtained from the "A" and "B" factories, machines in tenon forming have higher precision than the machines at factory " $\mathrm{C}$ ". The results obtained from the diagram " $\mathrm{X}$ " from the tenons samples for factories "A, B, C" indicate that reciprocal exchange of details can only be done between "B" and "C" factories because they have the approximate average tenon formation.

St.dev. "A" Mortises $=0.05$;

St.dev. "B" Mortises = 0.22;

St.dev. "C" Mortises = 0.14;

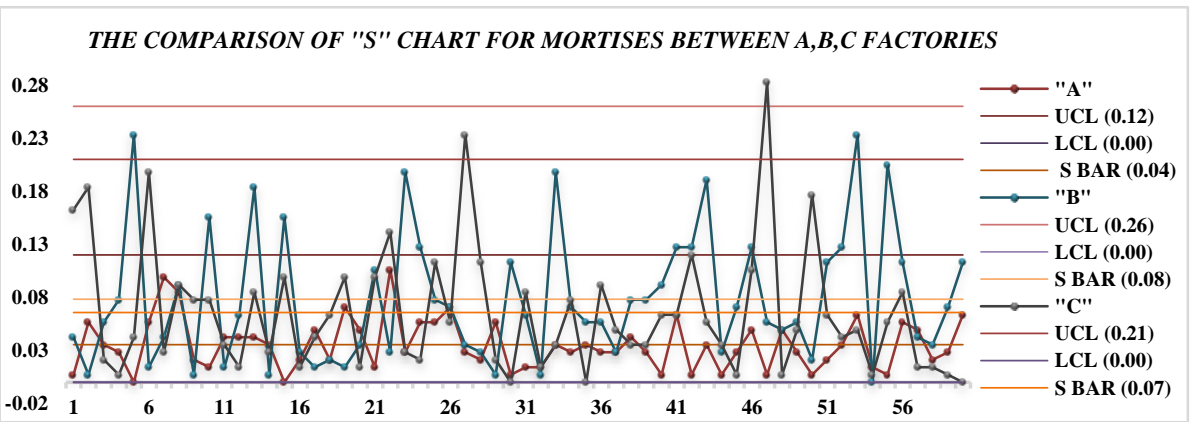

Figure 22. The comparison of standard deviation of mortises, between "A,B,C" factories. 
$\overline{\bar{X}} " \mathrm{~A} "$ Mortises $=10.06 ; \quad \overline{\bar{X}}$ "B" Mortises $=10.23 ; \quad \overline{\bar{X}}$ "C" Mortises = 10.44;

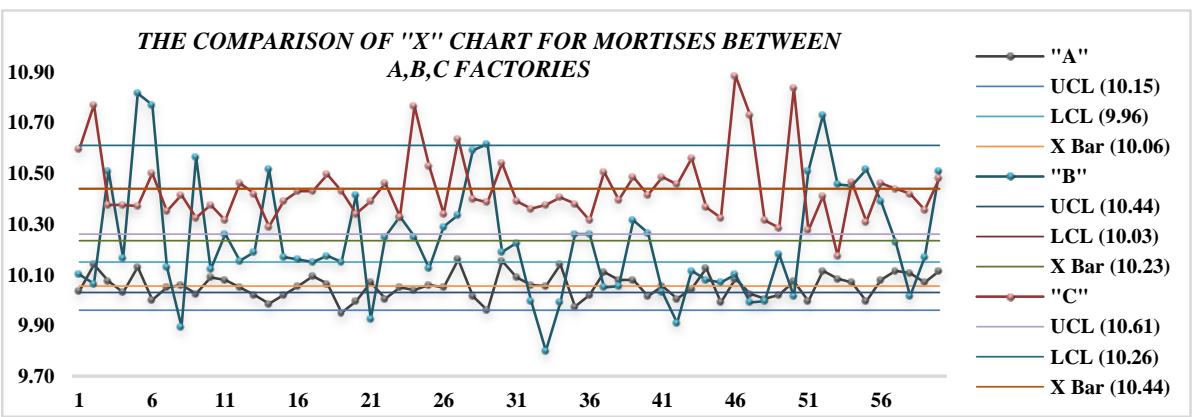

Figure 23. The comparison of arithmetic average of mortises, between "A,B,C" factories.

According to the chart "S", with the data of the for the mortise factories "A, B, C", we find that based on the standard deviation obtained, the "A" factory in martise forming has the higher precision, than the machines in factories "B" and " $\mathrm{C}$ ".

The results obtained from the diagram " $\mathrm{X}$ ", (figure 23.), from the mortise samples for the factories "A, B, C", show that reciprocal exchange of details can only be done between the "A, B". Because the sample distribution of the "B" factory fits more with the distribution of "A" samples, than with samples of factory "C", and they also have a same arithmetic average of samples.

\section{Conclusions}

From this study that has been carried out, we have these conclusions and recommendations are as follows:

1. Standard deviation for samples of each factory is:
Factory "A" (tenon) $=0.11 \mathrm{~mm}$
Factory "A" (mortise) $=0.05 \mathrm{~mm}$
Factory "B" (tenon) $=0.11 \mathrm{~mm}$
Factory "B" (mortise) $=0.22 \mathrm{~mm}$
Factory "C" (tenon) $=0.15 \mathrm{~mm}$
Factory "C" (mortise) $=0.14 \mathrm{~mm}$

Based on the standard deviation, the best results are notices in the "A" mortise forming, with a standard deviation of $0.05 \mathrm{~mm}$, while the worst results are found in the "B" factory with a standard deviation of $0.22 \mathrm{~mm}$.

2. The accuracy of the machines for forming the details according to the coefficient $\mathrm{c}$ for each factory is:

Factory "A" (tenon) $=0.60$

Factory "B" (tenon) $=0.60$

Factory "A" (mortise) $=0.30$

Factory "C" (tenon) $=0.90$

Factory "B" (mortise) $=1.20$

Factory "C" (mortise) $=0.90$

As for the greater precision of the machines for forming the details, more satisfying results are provided by the mortise-making machines at factory "A" with a precision of 0.30 . While the "B" mortise forming machine is less accurate, (during the formation of the details gives more defects) according to the standard deviation $(0.22 \mathrm{~mm})$ and the scale of accuracy $(1.20)$.

3. The reciprocal exchange of details (tenon-mortise) can be done between "B-C" and "A-B" factories. 
4. The flat surface of the processor affects the fixing of the detail during the process of its creation, without forming the right tenon but with deviations. This then presents problems in linking the details (tenon-mortise).

5. Machine maintenance should be done according to manufacturer's recommendations.

6. Maintenance of tools.

7. Leveling of the machine.

8. Stabilization of the machine

9. Lubrication of the machine.

\section{References}

1. Ymeri M. Teknologiia e përpunimit mekanik të drurit, Ligjerata të autorizuara për studentët e FSHTA-Ferizaj 2007/2008,

2. Sejdiu Rr. Menaxhimi i Cilësisë, Ligjerata të autorizuara për studentët e USHA-Ferizaj 2017 ,

3. Meta S. Struktura anatomike dhe Identifikimi i Drurit, Ligjerata të autorizuara për studentët e USHA-Ferizaj 2014,

4. Osmani O. Teknologjia e Finalizimit të Drurit, Universiteti i Prishtinës, FSHTA-Ferizaj Prishtinë 2001,

5. Osmani O. Makinat për Përpunimin e Drurit, Universiteti i Prishtinës, FSHTA-Ferizaj Prishtinë 2001,

6. Toska F. Materiale për prodhimin e objekteve prej druri, Ligjerata të autorizuara për studentët, Agjencia Kombëtare e Arsimit, Formimit Profesional dhe Kualifikimeve Shqipëri, Tiranë 2013, 